\title{
IMPLEMENTASI IME (ILEARNING MEDIA)DALAM MENDUKUNG SISTEM PEMBELAJARAN ILEARNING PADA PERGURUAN TINGGI
}

\author{
Untung Rahardja ${ }^{1}$ \\ Sudaryonoi ${ }^{2}$ \\ Irwan Nurdin ${ }^{3}$ \\ e-mail : untung@raharja.info; sudaryono@raharja.info; \\ irwan.nurdin@raharja.info
}

Diterima : 03 Juli 2014 / Disetujui: 21 Juli 2014

\begin{abstract}
The learning system is run in an educational institution, strongly influence the mindset and creativity of each student. In a learning system running on colleges Raharja, currently still using paper as a medium for performing tasks. The use of paper is a way of learning the manual and monotonous. To support that learning systems can be more interesting is to utilize existing information technology. iLearning is a method of lecturing in colleges Raharja who use the iPad as a media to facilitate the learning process of students. Given this method, students can learn, work, pray and play with iPad. The term is known as $4 B$. iLearning Media or shortened by the name iMe is a web application that is created and can be used by all students of colleges Raharja to explore their creativity in learning. This is an online learning system that facilitates student learning, because it can be done anywhere and anytime. It was concluded that the contribution of the iMe can be used as a medium of information for learning systems for the entire community colleges Raharja. Research methods used in conducting this research is the method of observation and literature.
\end{abstract}

Keywords : iLearning, iMe, Site, Colleges Raharja.

1. Dosen Jurusan Sistem Informasi, STMIK Raharja

Jl. Jend Sudirman No. 40 Modern Cikokol-Tangerang Telp. 5529692

2. Dosen Jurusan Sistem Komputer, STMIK Raharja

Jl. Jend Sudirman No. 40 Modern Cikokol-Tangerang Telp. 5529692

3. Mahasiswa Jurusan Sistem Informasi, STMIK Raharja

Jl. Jend Sudirman No. 40 Modern Cikokol-Tangerang Telp. 5529692 


\begin{abstract}
ABSTRAKSI
Sistem pembelajaran yang berjalan dalam suatu instansi pendidikan, sangat mempengaruhi pola pikir dan kreativitas setiap pelajar. Dalam sistem pembelajaran yang berjalan pada Perguruan Tinggi Raharja, saat ini masih menggunakan kertas sebagai media pengerjaan tugas. Penggunaan kertas merupakan cara pembelajaran yang manual dan monoton. Sehingga kegiatan pembelajaran kurang menarik dan mahasiswa tidak dapat mengeksplor kreativitasnya dalam belajar. Untuk mendukung agar sistem pembelajaran dapat lebih menarik adalah dengan memanfaatkan teknologi informasi yang ada. iLearning adalah metode perkuliahan di Perguruan Tinggi Raharja yang menggunakan media iPad untuk mempermudah proses pembelajaran mahasiswa. Dengan adanya metode ini maka mahasiswa dapat belajar, bekerja, berdoa dan bermain dengan iPad. Istilah tersebut dikenal dengan nama 4B. iLearning Media atau disingkat dengan nama iMe adalah aplikasi berupa site yang dibuat dan dapat digunakan oleh seluruh mahasiswa Perguruan Tinggi Raharja untuk mengeksplor kreativitasnya dalam belajar. Ini merupakan sistem pembelajaran online yang memudahkan mahasiswa dalam belajar, karena dapat dilakukan di manapun dan kapanpun. Maka disimpulkan bahwa kontribusi iMe dapat dijadikan media informasi untuk sistem pembelajaran bagi seluruh civitas Perguruan Tinggi Raharja. Metode penelitian yang digunakan dalam melakukan penelitian ini adalah metode observasi dan studi pustaka.
\end{abstract}

Kata Kunci : iLearning, iMe, Site, Perguruan Tinggi Raharja.

\title{
PENDAHULUAN
}

Teknologi informasi terus berkembang sesuai dengan kebutuhan dan kegiatan organisasi dalam menghadapi persaingan yang begitu ketat. Saat ini informasi tak lagi dapat diserap dengan mengandalkan perangkat-perangkat yang masih kuno dan serba manual, oleh karena itu peran komputer sangatlah penting dalam memberikan suatu solusi dan merupakan alat bantu yang cukup baik dalam memperbaiki sistem yang belum optimal. Selain itu, dengan adanya komputerisasi dapat mendukung dalam peninggkatan mutu pelayanan suatu organisasi sehingga dapat meningkatkan perkembangan organisasi tersebut.

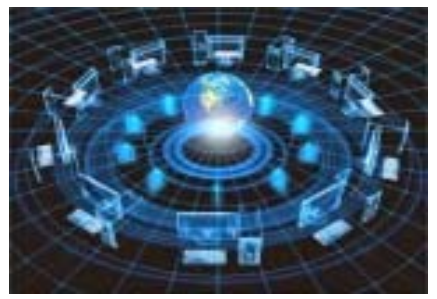

Gambar 1. Perkembangan Teknologi Informasi 
Perguruan Tinggi Raharja sebagai salah satu instansi atau lembaga pendidikan yang bergerak di bidang IT (Information Technologi) yang terus berinovasi dalam menciptakan media sistem informasi untuk kebutuhan sehari-hari. Dalam suatu sistem media informasi penyampaiannya masih menggunakan website, baik itu secara personal maupun teamwork. Namun mengingat semakin meningkatnya kebutuhan mahasiswa dan kualitas media informasi semakin baik, maka informasi yang dibutuhkan pun semakin meningkat khususnya mengenai media yang disampaikan dan media yang digunakan untuk penyampaian informasi, sehingga kualitas dan kuantitas sistem yang berjalan saat ini jauh lebih baik.

Perguruan Tinggi Raharja dalam fungsinya harus melayani segenap lapisan masyarakat yang tersebar di seluruh Indonesia, dengan berbagai keragaman yang terdapat di dalamnya. Keragaman tersebut mencakup berbagai macam aspek, antara lain tingkat ekonomi, kesempatan belajar, ketersediaan sarana dan prasarana untuk belajar, cara belajar, kecepatan belajar serta motivasi belajar.

Oleh karena itu, sebagai salah satu Perguruan Tinggi yang bergerak di bidang komputer harus selalu berinovasi untuk meningkatkan kualitas pembelajaran. Salah satunya adalah dengan menerapkan sistem pembelajaran iLearning. Pada dasarnya istilah iLearning (Integrated Learning) berasal dari pemikiran perkembangan teknologi iPad di Perguruan Tinggi Raharja. Belajar, bekerja, bermain, dan berdo’a merupakan konsep pembelajaran iLearning.

iLearning merupakan sistem pembelajaran yang efisien, praktis dan menyenangkan sehingga membuat mahasiswa menjadi lebih atrakrif dan semangat dalam belajar dengan didukung teknologi yang mempermudah jangkauan mahasiswa dalam melakukan interaksi. Berdasarkan tulisan mengemukakan bahwa iLearning adalah sistem pembelajaran modern dan terbaru dalam dunia pendidikan yang berbasis 4B (Belajar, Bekerja, Bermain, dan Berdo’a) dan dapat diimplementasikan sebagai infrastruktur 4B iLearning.[1], seperti gambar di bawah ini :

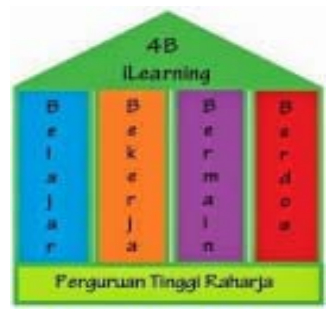

Gambar 2. Arsitektur 4B iLearning 
Sistem pembelajaran iLearning yang diterapkan di suatu Perguruan Tinggi harus saling berhubungan dan berkaitan satu sama lain. iLearning merupakan inovasi baru dalam dunia pendidikan yang memanfaatkan perkembangan teknologi informasi. Kini dengan adanya metode pembelajran iLearning, maka dapat mempermudah mahasiswa dalam melakukan proses belajar, khususnya dalam pengerjaan tugas.

\section{PERMASALAHAN}

Dalam sistem pembelajaran yang berjalan pada Perguruan Tinggi Raharja, saat ini masih menggunakan kertas sebagai media pengerjaan tugas. Penggunaan kertas merupakan cara pembelajaran yang manual dan monoton. Sehingga kegiatan pembelajaran kurang menarik dan mahasiswa tidak dapat mengeksplor kreativitasnya dalam belajar.

Untuk mengikuti perkembangan teknologi IT yang semakin berkembang, sebuah Perguruan Tinggi mesti melakukan inovasi dalam melaksanakan kegiatan akademik. Dalam hal ini sistem pembelajaran yang diimplementasikan. Perlu adanya sebuah inovasi baru, yakni diciptakannya sistem pembelajaran yang tidak lagi menggunakan kertas sebagai medianya. Sehinga lebih praktis dan efisien.

Dari permasalahan tersebut di atas dapat disimpulkan secara detail berdasarakan penjabaran tentang sistem pendukung yang tergambar dalam mind mapping di bawah ini:

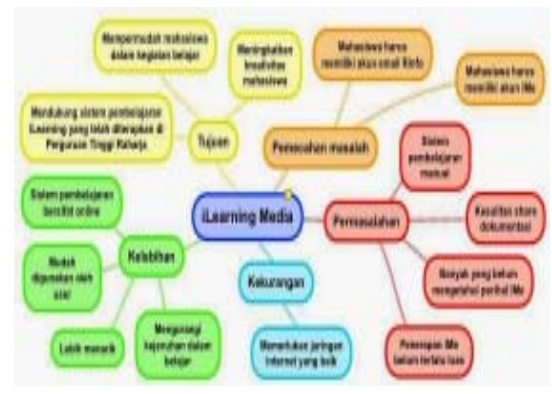

Gambar 3. Mind mapping penjabaran sistem iMe (iLearning Media)

Tampak pada gambar di atas adalah mind mapping penjabaran sistem iMe (iLearning Media). Dengan adanya iMe, diharapkan dapat diakses oleh seluruh mahasiswa dimanapun dan kapanpun. Selain itu juga diharapkan dapat meningkatkan 
kreativitas serta motivasi mahasiswa dalam belajar. Dan dapat menjadi sarana penunjang yang baik dalam menyampaikan dan memperoleh informasi yang akurat secara online dan up to date.

\section{METODE PENELITIAN}

Dalam melakukan penelitian ini penulis menggunakan 2 metode, yaitu :

\section{Observasi}

Adalah metode pengumpulan data melalui pengamatan atau peninjauan secara langsung di lapangan atau lokasi penelitian. Penelitian ini dilakukan pada Perguruan Tinggi Raharja yang menjadi lokasi penelitian guna memperoleh data dan keterangan yang berhubungan dengan jenis penelitian.

\section{Studi Pustaka}

Adalah segala upaya yang dilakukan oleh peneliti untukmemperoleh danmenghimpun segala informasi tertulis yang relevan dengan masalah yang diteliti. Pada metode ini penulis mendapatkan informasi dengan mempelajari buku-buku dan literature yang ada. Pada metode ini penulis akan mendapatkan informasi dengan memepelajari buku-buku dan literature yang ada seperti CCIT Journal Perguruan Tinggi Raharja.

\section{LITERATURE REVIEW}

Dalam upaya perlu dilakukan studi pustaka sebagai salah satu dari penerapan metode penelitian yang akan dilakukan. Diantaranya adalah mengidentifikasikan kesenjangan (identify gaps), menghindari pembuatan ulang (reinventing the wheel), mengidentifikasikan metode yang pernah dilakukan, serta mengetahui orang lain yang spesialisasi dan area penelitian yang sama dibidang ini. Beberapa literature review tersebut adalah sebagai berikut :

1. Penelitian yang dilakukan oleh Colin Beard, Jhon P. Wilson, Richard McCarter dari Sheffield Hallam University pada tahun 2007 dengan judul “Towards a Theory eLearning: Experiential eLearning” menjelaskan bahwa untuk mengembangkan iLearning dalam studi kasus ini adalah dengan menggunakan 
model yang dikembangkan dari teori belajar pengalaman praktis sebagai dasar untuk desain sebuah induksi CD-Room untuk mahasiswa. Sebuah model pengalaman informasi urutan dan pengembangan naskah film, yang kemudian dievaluasi melalui penggunaan quizioner, wawancara, dan menulis reflektif dengan mahasiswa pascasarjana. Experential learning erat melibatkan orang, sedangkan iLearning adalah interaksi media elektronik yang dimediasi.[2]

2. Penelitian yang dilakukan oleh Ida Bagus Nyoman Sudria, I Wayan Redhana, dan Luh Samiasihdari Universitas Pendidikan Ganesha pada tahun 2011 dengan judul "Pengaruh Pembelajaran Interaktif Laju Reaksi Berbantuan Komputer Terhadap Hasil Belajar Siswa“ menjelaskan bahwa hasil belajar siswa pada pembelajaran interaktif laju reaksi lebih tinggi (rerata skor 81,1) daripada hasil belajar siswa tanpa dukungan program interaktif laju reaksi berbantuan komputer (rerata skor 70,9) dengan nilaisignifikansi sebesar 0,000 $(\mathrm{p}<0,05)$ karena program pembelajaran interak-tif laju reaksi mampu menyajikan aspek mikros-kopis, makroskopis, dan simbolik serta menyajikan dukungan simulasi aspek statik dan dinamik dari partikel materi. Visualisasi dinamik partikel materi yang tidak kasat mata membantu siswa mengkonstruksi pengetahuannya dengan tepat sehingga menanggulangi bahkan mencegah terjadinya miskonsepsi siswa. siswa memberikan tanggapan positif terhadap pembelajaran dengan dukungan program pembelajaran interaktif laju reaksi berbantuan komputer.[3]

3. Penelitian yang dilakukan oleh Henderi, Maimunah, dan Randy Andrian dari Perguruan Tinggi Raharja pada tahun 2011 yang berjudul "Desain Aplikasi Elearning Sebagai Media Pembelajaran Artificial Informatics” menjelaskan bahwa articial information merupakan sebuah sistem informasi yang memiliki karakter dan kapabilitas seperti manusia dengan menggunakan PC dalam membantu menyelesaikan tugas sehari-hari. Artificial informatics menekankan bahwa sistem informasi harus "humanized” yaitu memiliki karakter yang sesuai dengan dimana sistem informasi itu berada. Dalam perancangan media pembelajaran e-learning artificial informatics ini melalui tahap yang terdiri dari : pembuatan desain global yang terdiri dari : Unified Modeling Language (UML) use case diagram dan class diagram. Situs web media e-learning artificial informatics yang telah dibangun dapat memberikan alternatif lain dalam mempelajari artificial informatics, karena memiliki fasilitas untuk memperbaharui data sehingga data yang ditampilkan selalu mengikuti perkembangan artificial informatics. Selain itu, web media ini memberikan 
kemudahan dalam mempelajari artificial informatics dengan tampilan yang interaktif.[4]

4. Penelitian yang dilakukan oleh Rano Kurniawan, Henderi, dan Fitria Nursetianingsih Perguruan Tinggi Raharja pada tahun 2012 dengan judul "Penggunaan Ipad Mendukung Pembelajaran Pada Mahasiswa iLearning“ menjelaskan bahwa untuk mendukung keefektifan metode pembelajaran iLearning diperlukan adanya sarana pendukung sebagai standarisasi. Didalam iPad terdapat aplikasi yang menudkung kegiatan iLearning. Dengan adanya iad, hal ini dapat memudahkan pembelajaran iLearning serta dapat menciptakan integritas yang baik untuk metode pembelajaran. Melalui satu sentuhan mahasiswa dapat menjelajah berbagai hal, sehingga tercipta jiwa iLearning dan ilmu pengetahuan yang dapat diserap secara efektif dan efisien sehingga mahasiswa memiliki kemampuan lebih dan selalu up to date dengan perkembangan ilmu pengetahuan maupun teknologi yang baru.[5]

5. Penelitian yang dilakukan oleh Untung Rahardja, Ary Budi Warsito, dan Dini Nurul Suvianti dari Perguruan Tinggi Raharja pada tahun 2012 dengan judul "Penerapan Aplikasi iDINI Sebagai Media Penyimpanan Materi Perkuliahan iLearning Pada Perguruan Tinggi“ menjelaskan bahwa perlu adanya perubahan metode pembelajaran yang dapat menciptakan suasana kelas serta membuat mahasiswa lebih bersemangat. Maka diperlukannya proses yang cepat dan efisien dalam mengakses seluruh data yang banyak terutama dalam media penyimpanan. Integrated Download iBooks in iPad disingkat menjadi iDINI, merupakan media pendukung pembelajaran iLearning yang berupa sebuah aplikasi. Penggunaan aplikasi ini sebagai media penyimpanan bahan ajar materi perkuliahan yang dapat meningkatkan aktivitas mahasiswa dalam pembelajaran iLearning.[6]

6. Penelitian yang dilakukan oleh Muhamad Yusup, Sri Rahayu, dan Desi Ermita dari Perguruan Tinggi Raharja pada tahun 2012 dengan judul “Desain Forum Diskusi Mahasiswa Sebagai Media Pembelajaran iLearning Pada Perguruan Tinggi“ menjelaskan bahwa proses belajar mengajar adalah inti aktivitas dalam pendidikan. Proses ini merupakan interaksi yang terjadi antara dosen dan mahasiswa serta dipengaruhi oleh hubungan yang ada dalam proses tersebut. Seiring dengan pesatnya perkembangan di dunia telekomunikasi yang ditandai dengan era digitalisasi, khususnya di bidang Teknologi Informasi dan Komunikasi (TIK). Perguruan Tinggi Raharja yang menerapkan konsep IT dalam proses belajar mengajar jelas memerlukan sarana dan prasarana TIK 
yang up to date untuk menunjang kegiatan serta peningkatan kualitas proses belajar mengajar. Salah satu sarana untuk menunjang proses belajare mengajar yaitu dengan konsep iLearning. Ilearning memanfaatkan teknologi internet sebagai sarana penyajian dan distribusi informasi. Disamping itu konsep pembelajaran iLearning sangat mendukung proses belajar mengajar karena perkembangannya membuat mahasiswa tidak malu dan ragu untuk mengungkapkan pertanyaan atau komentar yang mereka miliki karena tidak adanya tekanan psikologis yaitu tidak bertatap muka langsung dengan dosen. Namun agar forum diskusi online ini dapat diterapkan sebagai media pembelajaran iLearning hendaknya dilakukan proses penerapan konsep pembelajaran iLearning dengan desain pembelajaran yang benar, sehingga memungkinkan terjadinya proses belajar.[7]

Dari 6 (enam) literature review yang ada, telah banyak penelitian mengenai "Towards a Theory eLearning : Experiential eLearning”, "Pengaruh Pembelajaran Interaktif Laju Reaksi Berbantuan Komputer Terhadap Hasil Belajar Siswa”, “Desain Aplikasi E-learning Sebagai Media Pembelajaran Artificial Informatics”, "Penggunaan Ipad Mendukung Pembelajaran Pada Mahasiswa iLearning”, "Penerapan Aplikasi iDINI Sebagai Media Penyimpanan Materi Perkuliahan iLearning Pada Perguruan Tinggi”, "Desain Forum Diskusi Mahasiswa Sebagai Media Pembelajaran iLearning Pada Perguruan Tinggi”. Namun dapat disimpulkan pula bahwa belum ada peneliti yang membahas "Implementasi iMe (iLearning Media) Dalam Mendukung Sistem Pembelajaran iLearning Pada Perguruan Tinggi”.

\section{PEMECAHAN MASALAH}

Untuk mengatasi masalah di atas, maka diperlukan suatu sistem untuk mendukung sistem pembelajaran iLearning. Sistem tersebut adalah iMe (iLearning Media), merupakan sebuah official portal blogging yang dipersembahkan khusus untuk Pribadi Raharja, dan setiap Pribadi Raharja akan mendapatkan subdomain sebagai media dokumentasi segala bentuk aktivitas tridharma.. Dan iMe (iLearning Media) memiliki kelebihan yaitu mempunyai domain sendiri yang menciri khaskan perihal Perguruan Tinggi Raharja yaitu iLearning. iMe (iLearning Media) sangat mendukung kegiatan pembelajaran iLearning di Perguruan Tinggi Raharja.

Pengerjaan tugas dapat dikerjakan di dalam post maupun page yang akan menghasilkan tampilan hasil akhir yang sama. Hanya saja penempatan posisinya 
yang berbeda. Page terletak rapih dan dapat disusun sesuai keinginan pada menu, sedangkan post terletak sembarang sesuai dengan waktu pembuatannya. Hasil dari pengerjaan tugas tersebut akan diberikan oleh mahasiswa kepada dosen yang bersangkutan dalam bentuk link yang biasanya dikirim melalui iDu (iLearning Education). iDu (iLearning Education) merupakan sistem pembelajaran yang baru dikembangkan oleh Perguruan Tinggi Raharja secara online untuk memudahkan civitas kampus dan mahasiswa dalam menjalankan perkuliahan. iDu dapat diakses kapanpun dan dimanapun.

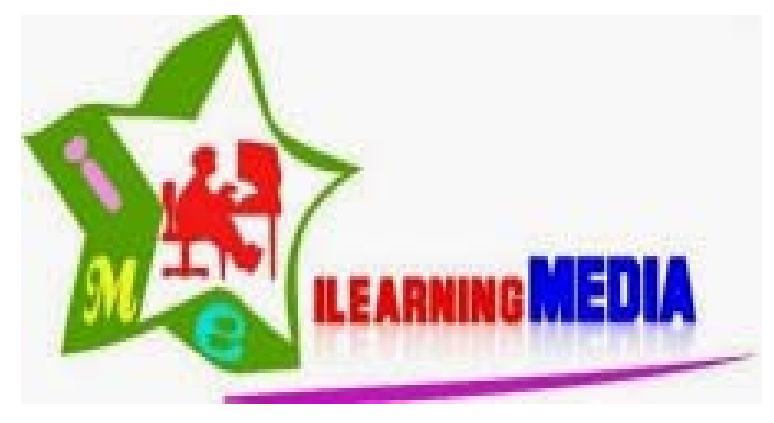

Gambar 4. Logo iMe

Setiap Pribadi Raharja yang ingin registrasi Site iMe harus telebih dahulu registrasi User iMe. Dan untuk registrasi User iMe harus menggunakan email Rinfo.

Jika sudah memiliki User iMe dan telah login, Pribadi Raharja bisa register Site iMe dengan cara request di http://ilearning.me/. Di halaman tersebut terdapat page dengan nama Request Site iMe yang di dalamnya terdapat form yang harus diisi oleh Pribadi Raharja yang ingin request Site iMe. Jika form tersebut telah diisi dengan lengkap, selanjutnya Pribadi Raharja harus submit. Setelah itu Pribadi Raharja harus cek email Rinfo, karena konfirmasi pembuatan Site iMe dilakukan melalui email. Melalui email tersebut, Pribadi Raharja akan menerima username dan password untuk login Site iMe.

Untuk memudahkan penjabaran dari sistem iMe (iLearning Media), maka dilakukan cara alternatif penggambaran sistem melalui alur flowchart. Di bawah ini merupakan alur flowchart dari sistem iMe (iLearning Media), mulai dari Register User iMe, Register Site iMe, dan Login iMe.

1. Flowchart Register User iMe 


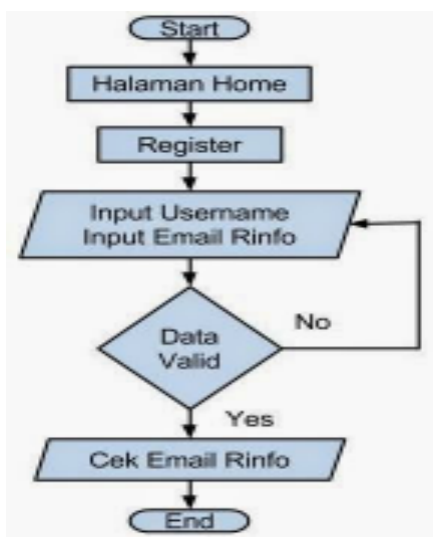

Gambar 5. Flowchart Register User iMe

Gambar di atas menjabarkan proses registrasi User iMe. Langkah pertama adalah mengunjungi halaman home http://ilearning.me/. Lalu pilih page Register. Kemudian menginputkan username dan email Rinfo.

\section{Flowchart Register Site iMe}

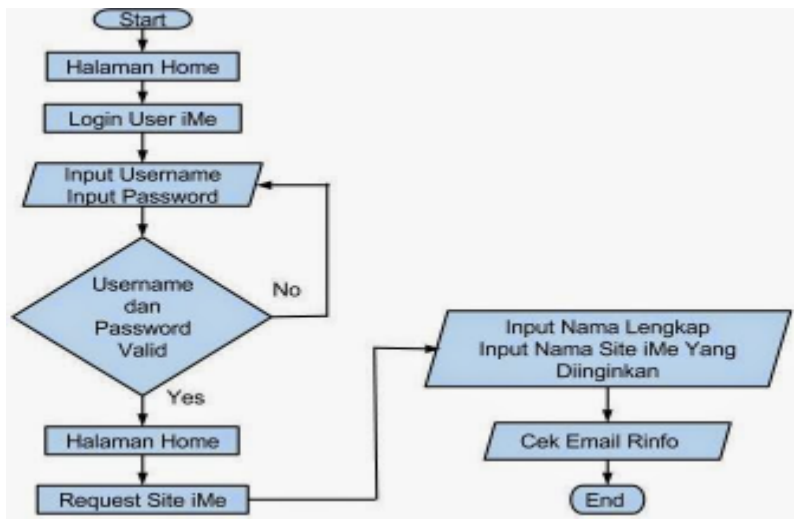

Gambar 6. Flowchart Register Site iMe

Gambar di atas menjabarkan proses registrasi Site iMe. Langkah pertama adalah mengunjungi halaman home http://ilearning.me/. Kemudian login User iMe. Setelah itu kembali buka halaman http://ilearning.me/. Lalu pilih page Request Site iMe, isi form registrasi. Jika sudah diisi lengkap selanjutnya submit form tersebut. 
Langkah terakhir adalah cek email Rinfo. Konfirmasi pembuatan Site iMe dikirim oleh admin melalui email Rinfo.

3. Flowchart Login iMe

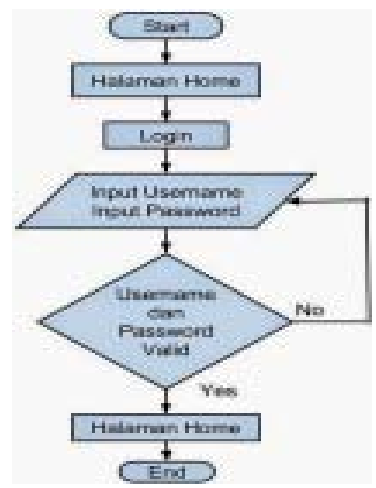

\section{Gambar 7. Flowchart Login iMe}

Gambar di atas menjabarkan proses login iMe. Dimulai dari mengunjungi halaman http://ilearning.me/. Lalu memasukkan username dan password. Jika username dan password yang dimasukkan valid, maka user berhasil masuk ke halaman home dalam keadaan login.

Diagram rancangan sistem iMe (iLearning Media) dapat pula dijabarkan dengan Use Case Diagram yang menggambarkan kebutuhan sistem dari sudut pandang User dan memfokuskan pada proses komputerisasi. Sebuah Use Case dapat menggambarkan hubungan antara Use Case dengan Actor. Secara umum, Use Case adalah pola perilaku sistem dan ukuran transaksi yang berhubungan yang dilakukan oleh satu Actor.

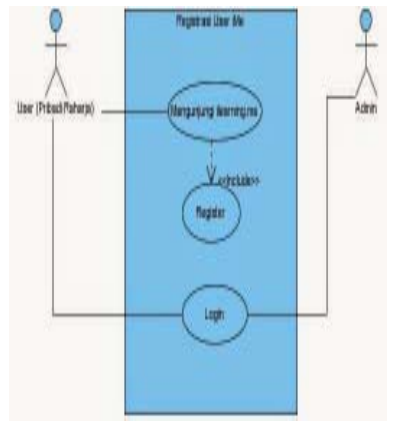

Gambar 8. Use Case Diagram Registrasi User iMe 
Gambar di atas menjabarkan bahwa untuk melakukan register User iMe, Pribadi Raharja mesti mengunjungi halaman http://ilearning.me/. Di halaman tersebut Pribadi Raharja dapat langsung melakukan registrasi.

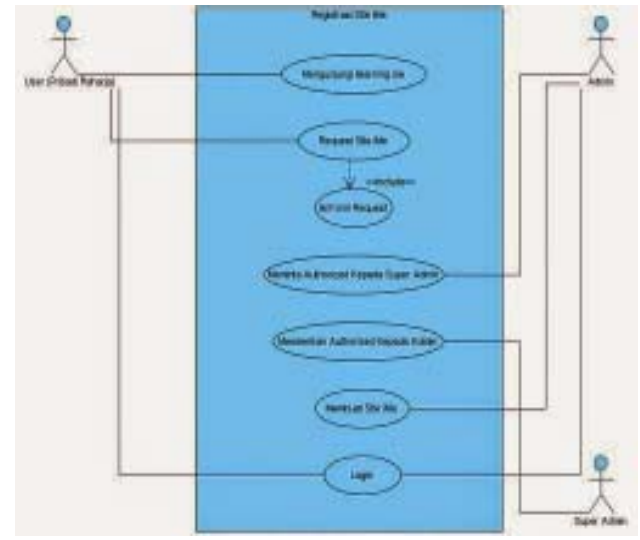

Gambar 9. Use Case Diagram Registrasi Site iMe

Gambar di atas menjabarkan bahwa Site iMe hanya dapat diaktifkan oleh admin. Untuk memiliki Site iMe, Pribadi Raharja mesti mengunjungi halaman http:// ilearning.me/ lalu pilih page "Request Site iMe”. Jika sudah dibuatkan oleh admin, maka langsung diinformasikan kepada Pribadi Raharja yang request tersebut melalui email Rinfo.

\section{IMPLEMENTASI}

iMe (iLearning Media) telah diimplementasikan pada Perguruan Tinggi Raharja dalam mendukung sistem pembelajaran iLearning. iMe (iLearning Media) merupakan media publikasi perihal data diri maupun segala jobdesk yang dikerjakan dalam jangka waktu tertentu.

DaniMe(iLeaming Media) memiliki kelebihan yaitumempunyai domain sendiri yang menciri khaskan perihal Perguruan Tinggi Raharja yaitu iLearning. iMe(iLearning Media) merupakan sebuah site yang dikemas secara khusus untuk kegiatan proses pembelajaran secara online di Perguruan Tinggi Raharja.

1. Tampilan halaman home iMe 
Halaman home merupakan tampilan yang pertama kali muncul saat user membuka site iMe, ilearning.me. Pada halaman home ini terdapat navigasi ke TPi (Ten Pillar iLearning), yaitu iMe, iRME, iDu, iRAN, iSur, MAGICS, Rooster, iDuHelp!, Widuri, dan Rinfo.

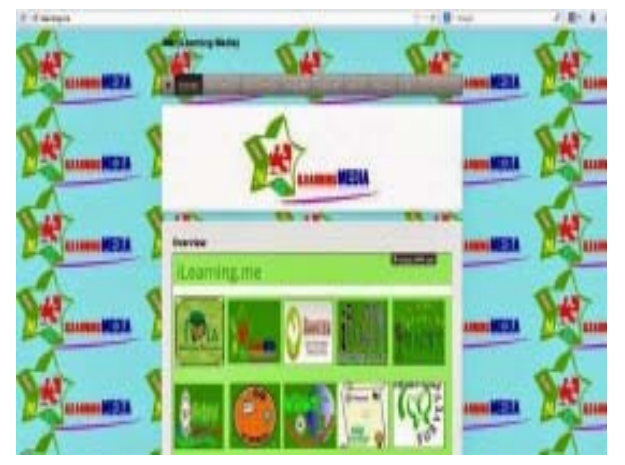

Gambar 10. Tampilan Halaman Home iMe

\section{Tampilan Halaman Dashboard}

Dashboard adalah tempat pengelolaan site untuk user dalam mengelola content, tampilan, widget, dan lainnya.

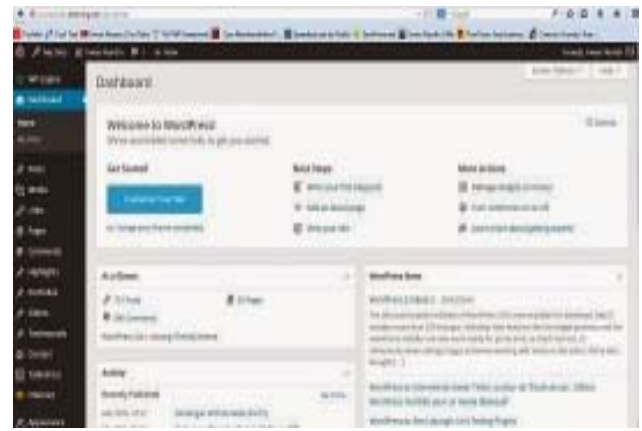

Gambar 11. Tampilan Halaman Dashboard iMe

\section{Tampilan Halaman Add New Post}

Halaman add new post adalah tempat user membuat postingan baru. User bisa membuat postingan baru dengan memasukkan judul dan isi postingan, lalu klik publish. Maka postingan terpublish. 


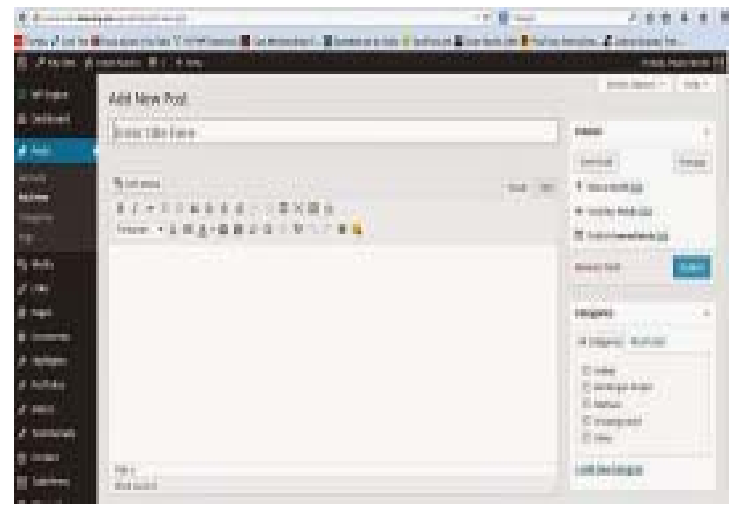

Gambar 12. Tampilan Halaman Add New Post iMe

\section{Tampilan Halaman Add New Page}

Halaman add new page adalah tempat user membuat page baru. User bisa membuat page baru dengan memasukkan judul dan isi page, lalu klik publish. Maka page terpublish.

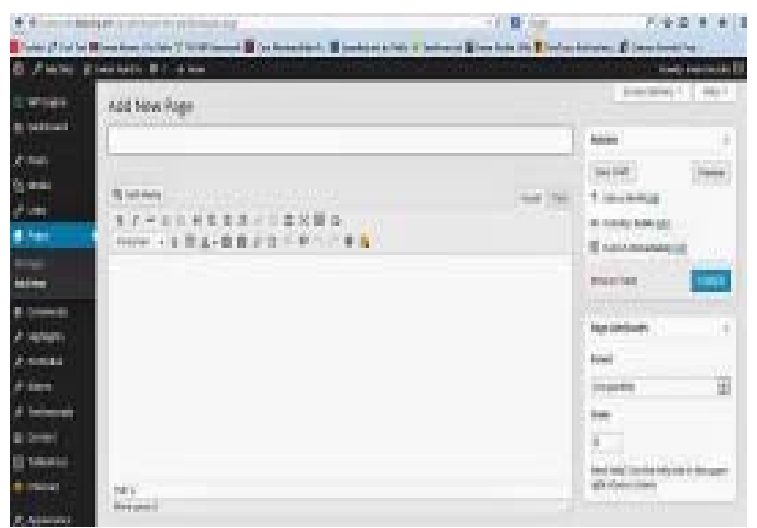

Gambar 13. Tampilan Halaman Add New Page iMe

5. Tampilan Halaman Menu

Halaman menu adalah tempat user mengelola page-page yang ada. User bisa mengatur posisi-posisi page sesuai keinginan. 


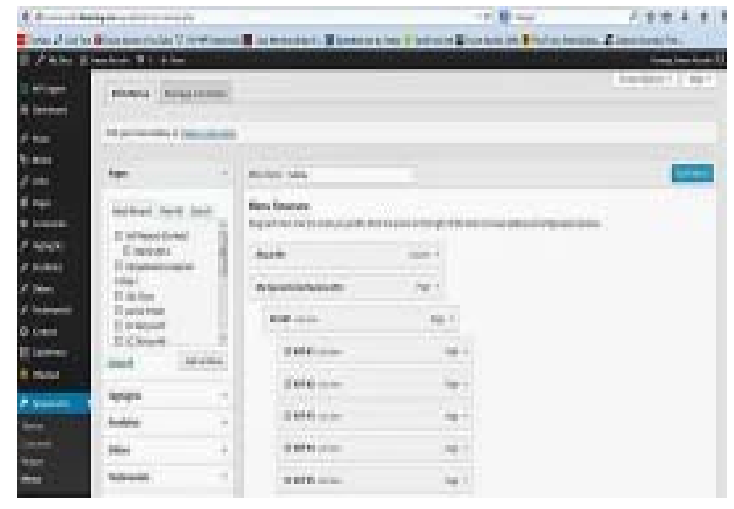

Gambar 14. Tampilan Halaman Menu iMe

\section{KESIMPULAN}

iMe adalah official portal blogging yang dipersembahkan untuk Pribadi Raharja dan setiap Pribadi Raharja akan mendapatkan subdomain sebagai media dokumentasi segala bentuk aktifitas tridarma. Implementasi iMe (iLearning Media) ini diharapkan dapat diakses oleh seluruh mahasiswa dimanapun dan kapanpun. Selain itu juga agar dapat meningkatkan kreativitas serta motivasi mahasiswa dalam belajar. Dan dapat menjadi sarana penunjang yang baik dalam menyampaikan dan memperoleh informasi yang akurat secara online dan up to date.

Selain itu juga dapat lebih memaksimalkan sistem informasi pembalajaran kampus di Perguruan Tinggi Raharja, adanya sistem pembelajaran kampus online yang dapat dilakukan dimana saja dan kapan saja, meningkatkan kreativitas mahasiswa, meningkatkan motivasi mahasiswa dalam belajar, adanya sistem pembelajaran yang tidak manual, mencerminkan kampus IT dengan memanfaatkan perkembangan teknologi, sehingga dapat memperluas jaringan dan menghasilkan informasi yang akurat.

Selain itu, iMe juga memiliki tampilan yang user friendly sehingga penggunanya dapat dengan mudah mengenal sistem ini. iMe bukan hanya digunakan oleh mahasiswa Perguruan Tinggi Raharja, melainkan juga dosen dan manajemen Perguruan Tinggi Raharja. iMe (iLearning Media) dapat meningkatkan kreativitas serta motivasi belajar dari mahasiswa, dapat dilakukan dimanapun dan kapanpun, serta dapat dijadikan 
sebagai media informasi bagi seluruh civitas perguruan tinggi dan masyarakat secara umum.

iMe (iLearning Media) dapat meningkatkan kreativitas serta motivasi belajar dari mahasiswa, dapat dilakukan dimanapun dan kapanpun, serta dapat dijadikan sebagai media informasi bagi seluruh civitas perguruan tinggi dan masyarakat secara umum.

\section{DAFTAR PUSTAKA}

[1] Untung Rahardja. "iLearning an Effective Learning Method for Higher Education”. Perguruan Tinggi Raharja. 2011

[2] Colin Beard, Jhon P. Wilson, Richard McCarter.“Towards a Theory eLearning: Experiential eLearning” Journal of Hospitality, Leisure, Sport and Tourism Education Vol 6 No 2 ISSN:1473-8376

[3] Ida Bagus Nyoman Sudria, I Wayan Redhana, dan Luh Samiasih. "Pengaruh Pembelajaran Interaktif Laju Reaksi Berbantuan Komputer Terhadap Hasil Belajar Siswa”. Universitas Pendidikan Ganesha. Jurnal Pendidikan dan Pengajaran. Vol 44. No 1. 2011

[4] Henderi, Maimunah, dan Randy Andrian. "Desain Aplikasi E-learning Sebagai Media Pembelajaran Artificial Informatics”. Perguruan Tinggi Raharja. 2011

[5] Rano Kurniawan, Henderi, dan Fitria Nursetianingsih. "Penggunaan Ipad Mendukung Pembelajaran Pada Mahasiswa iLearning”. Perguruan Tinggi Raharja. 2011

[6] Untung Rahardja, Ary Budi Warsito, dan Dini Nurul Suvianti. "Penerapan Aplikasi iDINI Sebagai Media Penyimpanan Materi Perkuliahan iLearning Pada Perguruan Tinggi”. Perguruan Tinggi Raharja. 2012

[7] Muhamad Yusup, Sri Rahayu, dan Desi Ermita. "Desain Forum Diskusi Mahasiswa Sebagai Media Pembelajaran iLearning Pada Perguruan Tinggi”. Perguruan Tinggi Raharja. 2012 